\title{
Work-Related Psychosocial Factors and Mental Health Problems Associated with Musculoskeletal Pain in Nurses: A Cross-Sectional Study
}

\author{
Tiina Freimann, ${ }^{1,2}$ Mati Pääsuke, ${ }^{3}$ and Eda Merisalu ${ }^{4}$ \\ ${ }^{1}$ Tartu University Hospital, Puusepa 1a, 50406 Tartu, Estonia \\ ${ }^{2}$ Institute of Family Medicine and Public Health, Faculty of Medicine, University of Tartu, Ravila 19, \\ 50411 Tartu, Estonia \\ ${ }^{3}$ Institute of Exercise Biology, University of Tartu, Ravila 14a, 50411 Tartu, Estonia \\ ${ }^{4}$ Institute of Technology, Estonian University of Life Sciences, Kreutzwaldi 56, 51014 Tartu, Estonia \\ Correspondence should be addressed to Tiina Freimann; tiina.freimann@kliinikum.ee
}

Received 2 June 2016; Accepted 12 October 2016

Academic Editor: Mary-Ann Fitzcharles

Copyright (C) 2016 Tiina Freimann et al. This is an open access article distributed under the Creative Commons Attribution License, which permits unrestricted use, distribution, and reproduction in any medium, provided the original work is properly cited.

Background. Musculoskeletal pain is the most common cause of incapacity among nurses. This study aimed to report the prevalence of musculoskeletal pain among hospital nurses and to explore the associations of work-related psychosocial factors and mental health problems with musculoskeletal pain. Methods. A cross-sectional survey was carried out among registered nurses at Tartu University Hospital during April and May 2011. Binary logistic regression was used to assess the associations between dependent and independent variables. Results. Analysis was based on 404 nurses (45\% of the hospital's nursing population). The overall prevalence of MSP was $70 \%$ in the past year and 64\% in the past month. Lower back (57\%) and neck (56\%) were the body areas most commonly painful in the past year. Higher quantitative and emotional demands, work pace, low justice and respect in the workplace, influence on work organisation, and role conflicts were significantly associated with musculoskeletal pain among nurses $(p<0.05)$. All mental health problems and most strongly somatic stress symptoms were associated with musculoskeletal pain. Conclusions. Workrelated psychosocial risk factors and mental health problems, especially somatic stress symptoms, have an important impact on the occurrence of musculoskeletal pain among university hospital nurses.

\section{Background}

According to 2014 Estonian Health Board statistics, musculoskeletal disorders account for $74 \%$ of all occupational diseases in Estonia and were the most common reason for receiving medical absence benefits [1]. Globally, nurses are one of the occupational groups with high prevalence of musculoskeletal pain (MSP) [2-10], which results in adverse health consequences for individuals, health care institutions, and society.

Epidemiologic studies have demonstrated that workrelated physical and psychosocial factors (PSFs) and individual characteristics play an important role in the development of MSP [11]. These risk factors have independent or interactive effects on the development of MSP and they may affect
MSP directly or indirectly as a result of individuals' stress experience [12,13]. Risk factors may reinforce each other and or their effects may be mediated by cultural factors and health beliefs [14]. The literature review of Sherehiy et al. (2004) provides evidence that work-related PSFs, especially work organisation problems and social relationships at work, are strongly related to musculoskeletal outcomes in the nursing population [15].

Previous studies in Estonia have shown high prevalence of MSP and mental health problems (MHPs) (including stress, burnout, and somatic stress symptoms) among university hospital nurses $[16,17]$. The occurrence of MSP in nurses was associated with physical work load, emotional exhaustion, and somatic stress symptoms [16]. Somatic stress symptoms were associated with several PSFs, including 
workload, emotional demands, social relationships, trust regarding the management, and justice, and respect in the workplace [17]. However, due to multifactorial nature of MSP, earlier studies have given controversial information about the risk factors for MSP. The aim of our study was to describe the prevalence of MSP and to explore the associations of work-related PSFs and MHPs with MSP among nurses at the university hospital in Estonia.

\section{Methods}

A cross-sectional study was carried out among registered nurses during April and May 2011 at Tartu University Hospital (TUH), Estonia. All 906 full-time registered nurses who had been employed at the hospital for at least one year were invited to complete an electronic questionnaire. Three reminders of the survey were sent to these nurses over a six-week period. In total, 409 nurses have completed the questionnaire (response rate $45 \%$ ). The study was approved by the Research Ethics Committee of the University of Tartu (protocol number 202T-19) and conducted in accordance with the Helsinki Declaration. The voluntary and anonymous nature of participation was emphasized in the letter of invitation and through verbal communication.

The questions from the Nordic Musculoskeletal Questionnaire (NMQ) were used to assess the prevalence of MSP at six anatomical areas of the body (lower back, neck, shoulder, elbow, wrist/hand, and knee) lasting for longer than a day during the past year and past month [18]. Information about sociodemographic characteristics and work history was also collected. Version two of the Copenhagen Psychosocial Questionnaire (COPSOQ II) was used to evaluate work-related PSFs and MHPs among the participants [19]. Work-related PSFs were assessed using 85 items grouped into 24 scales that covered the following five psychosocial domains: demands at work; work organisation and job contents; interpersonal relationships and leadership; the work-individual interface; and values in the workplace. MHPs were measured using 24 items grouped into 6 scales: sleeping troubles, burnout, stress, depression symptoms, somatic stress symptoms, and cognitive stress symptoms.

Statistical analysis was performed using IBM SPSS Statistics for Windows Version 24.0 (IBM Corp., Armonk, NY). First, descriptive statistics were used to analyse the data. The number and percentage were calculated to describe the prevalence of MSP in the past year and past month. For the analysis of PSFs all the items were scored from 0 to 100 points (the five response options were $0,25,50,75$, and 100 and the four response options $0,33.3,66.7$, and 100) to make the scoring on the different scales comparable [20]. The total score on a scale was the mean of the scores of the individual items. Binary logistic regression was used to assess the associations of work-related PSFs and MHPs with MSP and summarised by odds ratios (ORs) with $95 \%$ confidence intervals (CIs). For regression analysis, the five and four response options were used. In each analysis, the nurses who did not have the outcome under consideration were included in the referent category.
TABLE 1: Participants' demographic and lifestyle characteristics.

\begin{tabular}{|c|c|c|}
\hline Variable & $N$ & $\%$ \\
\hline \multicolumn{3}{|l|}{ Age (years) } \\
\hline $22-29$ & 88 & 21.8 \\
\hline $30-39$ & 116 & 28.7 \\
\hline $40-49$ & 105 & 26.0 \\
\hline $50-59$ & 95 & 23.5 \\
\hline \multicolumn{3}{|l|}{ Gender } \\
\hline Female & 401 & 98.30 \\
\hline Male & 7 & 1.7 \\
\hline \multicolumn{3}{|l|}{ Occupation } \\
\hline Nursing & 323 & 79.9 \\
\hline Nursing management & 81 & 20.1 \\
\hline \multicolumn{3}{|l|}{ Work tenure } \\
\hline$<5$ & 80 & 19.8 \\
\hline $5-10$ & 96 & 23.8 \\
\hline$>10$ & 228 & 56.4 \\
\hline \multicolumn{3}{|l|}{ BMI } \\
\hline$\leq 24.9$ & 207 & 51.2 \\
\hline$\geq 25.0$ & 197 & 48.8 \\
\hline \multicolumn{3}{|c|}{ Taking pain medicine during the past 3 months } \\
\hline Never & 60 & 14.9 \\
\hline Seldom & 140 & 34.6 \\
\hline One to several times a month & 115 & 28.5 \\
\hline One to several times a week & 73 & 18.0 \\
\hline Every day & 16 & 4.0 \\
\hline \multicolumn{3}{|l|}{ Smoking } \\
\hline Never and ex-smoker & 322 & 79.7 \\
\hline Current smoker & 82 & 20.3 \\
\hline \multicolumn{3}{|c|}{ Alcohol drinking during the past 3 months } \\
\hline Never & 95 & 23.5 \\
\hline Seldom & 176 & 43.6 \\
\hline One to several times a month & 101 & 25.0 \\
\hline One to several times a week & 25 & 6.2 \\
\hline Every day & 7 & 1.7 \\
\hline
\end{tabular}

\section{Results}

The questionnaires were completed by 409 of the 906 nurses invited to take part in the study (a response rate of $45 \%$ ). After checking for compliance with the criteria, five respondents were excluded because they had worked at the hospital for less than a year. A total of 404 questionnaires were used in the analysis.

Table 1 shows the demographic and lifestyle factors of the participants. Most of the nurses were women (98\%) and their ages ranged from 23 to 69 with a mean age of 40 . More than half of the participants (56\%) had worked in their job for more than 10 years and one-fifth were employed as nursing managers. Among the participants, 51\% of the nurses used analgesics for MSP more than once a month. Current smokers constituted $20 \%$ of the participants, and $25 \%$ of nurses used alcohol one or more times per month. 
TABLE 2: Work-related psychosocial factors and mental health problems for 404 nurses.

\begin{tabular}{|c|c|c|c|}
\hline Psychosocial factors (scales) & Number of items & Mean & $95 \% \mathrm{CI}$ \\
\hline \multicolumn{4}{|l|}{ Work demands } \\
\hline Quantitative demands (workload) & 4 & 32.2 & $30.5-33.9$ \\
\hline Work pace & 3 & 66.3 & $64.8-68.0$ \\
\hline Cognitive demands & 4 & 67.2 & $65.6-68.7$ \\
\hline Emotional demands & 4 & 57.1 & $55.3-58.8$ \\
\hline Expectations of hiding emotions & 3 & 73.3 & $71.6-75.1$ \\
\hline \multicolumn{4}{|l|}{ Work organisation and job contents } \\
\hline Influence on work organisation & 4 & 33.3 & $31.3-35.4$ \\
\hline Possibilities for development & 4 & 68.6 & $67.1-70.2$ \\
\hline Meaning of the work & 3 & 80.2 & $78.7-81.7$ \\
\hline Commitment to the work & 4 & 63.7 & $61.7-65.6$ \\
\hline \multicolumn{4}{|c|}{ Interpersonal relationships and leadership } \\
\hline Access to the information & 2 & 63.2 & $61.2-65.3$ \\
\hline Rewards (recognition) & 3 & 57.6 & $55.5-59.7$ \\
\hline Role clarity & 3 & 78.9 & $77.5-80.2$ \\
\hline Role conflicts & 4 & 35.9 & $34.0-37.8$ \\
\hline Quality of leadership & 4 & 59.6 & $57.4-61.9$ \\
\hline Social support from colleagues & 3 & 59.9 & $57.8-62.0$ \\
\hline Social support from supervisor & 3 & 57.8 & $55.2-60.5$ \\
\hline Social relationships at work & 3 & 71.4 & $69.5-73.4$ \\
\hline \multicolumn{4}{|l|}{ Work-individual interface } \\
\hline Job insecurity & 4 & 18.4 & $16.4-20.3$ \\
\hline Job satisfaction & 4 & 65.5 & $64.0-66.9$ \\
\hline Work-family conflict & 4 & 43.5 & $40.9-46.0$ \\
\hline \multicolumn{4}{|l|}{ Values in the workplace } \\
\hline Mutual trust between employees & 3 & 71.1 & $69.2-73.0$ \\
\hline Trust regarding management & 4 & 63.7 & $62.3-65.2$ \\
\hline Justice and respect & 4 & 49.3 & $46.8-51.9$ \\
\hline Social inclusiveness & 4 & 61.3 & $59.8-62.9$ \\
\hline \multicolumn{4}{|l|}{ Mental health problems } \\
\hline Stress & 4 & 41.2 & $39.5-42.8$ \\
\hline Somatic stress symptoms & 4 & 30.8 & $29.3-32.3$ \\
\hline Cognitive stress symptoms & 4 & 26.6 & $25.0-28.1$ \\
\hline Depression symptoms & 4 & 30.9 & $29.3-32.5$ \\
\hline Sleeping troubles & 4 & 32.7 & $30.7-34.6$ \\
\hline Burnout & 4 & 45.1 & $43.4-46.7$ \\
\hline
\end{tabular}

Table 2 presents the mean scores and 95\% confidence intervals for self-reported PSFs and MHPs. The work-related PSFs with the highest mean scores were meaning of work; role clarity; expectation of having to hide emotions; social relationships at work; mutual trust between employees. The lowest mean scores were recorded for job insecurity; workload; influence on work organisation; role conflicts; and work-family conflict. Stress and burnout showed the highest mean scores for MHPs.

Seventy percent of the participants reported having at least one body area with MSP lasting for longer than a day within the past year, and 64\% reported having MSP in the past month (Table 3). The lower back and neck were the sites most often affected by pain.

Table 4 presents the associations of PSFs and MHPs with MSP over the past year and past month. Work-related PSFs such as high quantitative and emotional demands, work pace, low justice and respect in the workplace, and role conflicts were significantly associated with MSP among nurses. Work-individual interface factors such as job dissatisfaction and work-family conflicts also showed positive correlation with MSP. The most significant associations were observed between somatic stress symptoms (stomach ache; headache; palpitations; tension in various muscles) and MSP. 
TABLE 3: Prevalence of musculoskeletal pain in the past year and past month.

\begin{tabular}{lcccc}
\hline \multirow{2}{*}{ Body area with pain } & \multicolumn{2}{c}{ Past year } & \multicolumn{2}{c}{ Past month } \\
& $N$ & $\%$ & $N$ & $\%$ \\
\hline Lower back & 230 & 56.9 & 159 & 39.4 \\
Neck & 225 & 55.7 & 174 & 43.1 \\
Shoulder & 125 & 30.9 & 106 & 26.2 \\
Elbow & 50 & 12.4 & 40 & 9.9 \\
Wrist/hand & 81 & 20.0 & 65 & 16.1 \\
Knee & 126 & 31.2 & 93 & 23.0 \\
MSP in any body part & 283 & 70.0 & 257 & 63.6 \\
\hline
\end{tabular}

Note. All percentages are calculated from the total sample $(N=404)$.

\section{Discussion}

Our study indicated that as in many other countries [2-10] MSP is quite common among TUH nurses. The prevalence of MSP in any body area occurred in 70\% of nurses over the past year, which was lower than in a previous study in Estonia (84\%) [16]. There could be several reasons for this variation, but one of them could be related to the differences in study design. The smaller sample size and higher prevalence of MSP in the preliminary study could have been due to subjects with pain being more interested in participating in the first study in our university hospital. Another reason may be the time during which the data were collected. While the previous study was performed from October 2008 to February 2009 (autumn/winter), the present study was carried out during April and May 2011 (spring). The effect of season on the occurrence of MSP has received insufficient attention in scientific literature.

The prevalence of MSP varies across countries and studies. For example, very different prevalence of MSP was obtained in two Swedish studies $[9,21]$. According to the research of Nilsson et al. (2010) [21], the prevalence of MSP among Swedish nurses was significantly lower compared to the results of a study by Josephson et al. (1997) [9] and with those from other countries. The decrease in MSP prevalence among nurses in Sweden may be supported by the long period between the two surveys. However, a difference in the prevalence of MSP among nurses within the same country has also been found in Japan $[5,22]$, where the studies were carried out at shorter intervals.

Comparing the mean scores of work-related PSFs between Estonian and US nurses [23], higher values occurred among Estonian nurses for the following factors: meaning of work; role clarity; access to the information; mutual trust between employees. Lower comparative scores for Estonian nurses occurred for workload, role conflicts, and their influence on the work organisation. In comparison with other salaried workers in Estonia [24], TUH nurses provided higher scores for work pace and emotional demands and lower scores for social relationships at work and social support from supervisors. Influence on work organisation and justice and respect in the workplace were also scored quite low (33 and 49 on a 100-point scale). A low influence on the work organisation seems to be a common problem for nurses also in the other countries, for example, in Denmark (33) and the US $(46)[23,25]$. The meaning of low influence on work organisation is expressed in terms that often the nurses have no choice in deciding on the amount of work and how or what to do at work.

Justice and respect in our study was scored considerably lower than for other salaried workers in Estonia (64.9) [24]. A low level of justice and respect has not been mentioned as a risk factor in earlier studies, but it was found to be associated with the occurrence of MSP in present study. There are a number of strategies that could be used to promote justice and respect at the workplace. Based on the results of present study, it is important to ensure that the nurses' work would be shared and conflicts at the workplace would be resolved in a fair way. All suggestions from the nurses should be treated more seriously by the management and the nurses should be appreciated when they have done a good job.

High quantitative and emotional demands, work pace, influence on work organisation, and role conflicts were found to be associated with MSP among TUH nurses. These results are similar to previous studies that have been conducted among nurses [3, 10, 26, 27]. Based on these results, it would be important to monitor nurses' work pace and quantitative and emotional job demands and to analyse work roles and work organisation. Work-individual interface factors such as job dissatisfaction and work-family conflicts also played a role in the occurrence of MSP. Van der Heijden et al. (2008) examined work-home interference among nurses and found that it could mediate the effects of job demands on health [28]. The hypothesis that family-work interference factors mediate the effects of psychosocial risk factors on MSPs would require further investigation. Although all MHPs were associated with MSP, the most significant association was observed however between somatic stress symptoms (stomach ache; headache; palpitations; tension in various muscles) and MSP. This finding supports an earlier study [29], in which somatic symptoms were found to be the leading determinant of MSP. A previous international CUPID (Cultural and Psychosocial Influences on Disability) study in Estonia and other countries demonstrated also positive associations between distressing somatic symptoms and MSP among nurses [16, 29-31].

Older age and perceived poor health were important risk factors for the occurrence of MSP in TUH nurses. This is in agreement with the findings of other researchers $[3,15,21]$. Because of that, all regression analyses in this study were adjusted for age and self-rated health. Surprisingly, most of the negative lifestyle factors (smoking, alcohol use, and taking pain medicines) were not associated with MSP among TUH nurses, as they have found to be risk factors in previous studies $[3,10]$. A weak association concerning MSP in the past month was found only between body mass index and length of service.

In summary, our study supports the earlier international scientific knowledge about the associations of work-related PSFs and MHPs with the occurrence of MSP in nursing profession and provides some additional information about possible effect of justice and respect on the prevalence of MSP among nurses. 
TABLE 4: Associations with musculoskeletal pain in past year and month.

\begin{tabular}{|c|c|c|}
\hline Psychosocial factors (scales) & $\begin{array}{l}\text { MSP in the past year } \\
\text { OR }^{*}(95 \% \mathrm{CI})\end{array}$ & $\begin{array}{l}\text { MSP in the past month } \\
\text { OR }^{*}(95 \% \mathrm{CI})\end{array}$ \\
\hline \multicolumn{3}{|l|}{ Work demands } \\
\hline Quantitative demands (workload) & $1.13(1.02-1.25)$ & $1.09(1.00-1.20)$ \\
\hline Work pace & $1.14(0.99-1.31)$ & $1.17(1.04-1.32)$ \\
\hline Cognitive demands & $1.12(1.01-1.25)$ & $1.08(0.99-1.19)$ \\
\hline Emotional demands & $1.10(1.00-1.24)$ & $1.17(1.08-1.28)$ \\
\hline Expectations of hiding emotions & $1.06(0.95-1.20)$ & $1.06(0.95-1.17)$ \\
\hline \multicolumn{3}{|l|}{ Work organisation and job contents } \\
\hline Influence on work organisation & $0.88(0.81-0.96)$ & $0.92(0.85-0.99)$ \\
\hline Possibilities for development & $1.01(0.91-1.12)$ & $1.01(0.92-1.11)$ \\
\hline Meaning of the work & $1.02(0.89-1.17)$ & $1.01(0.90-1.15)$ \\
\hline Commitment to the work & $0.96(0.88-1.05)$ & $0.98(0.91-1.06)$ \\
\hline \multicolumn{3}{|l|}{ Interpersonal relationships and leadership } \\
\hline Access to the information & $0.92(0.78-1.08)$ & $0.89(0.77-1.03)$ \\
\hline Rewards (recognition) & $0.92(0.82-1.03)$ & $0.92(0.84-1.01)$ \\
\hline Role clarity & $0.99(0.85-1.15)$ & $0.96(0.85-1.10)$ \\
\hline Role conflicts & $1.09(1.00-1.19)$ & $1.09(1.01-1.17)$ \\
\hline Quality of leadership & $0.94(0.87-1.02)$ & $0.98(0.92-1.05)$ \\
\hline Social support from colleagues & $0.85(0.76-0.95)$ & $0.96(0.88-1.06)$ \\
\hline Social support from supervisor & $0.94(0.86-1.02)$ & $1.01(0.94-1.08)$ \\
\hline Social relationships at work & $0.89(0.78-1.02)$ & $0.90(0.81-1.01)$ \\
\hline \multicolumn{3}{|l|}{ Work-individual interface } \\
\hline Job insecurity & $1.01(0.92-1.11)$ & $0.97(0.89-1.05)$ \\
\hline Job dissatisfaction & $1.19(1.02-1.39)$ & $1.16(1.01-1.33)$ \\
\hline Work-family conflict & $1.14(1.03-1.25)$ & $1.17(1.07-1.27)$ \\
\hline \multicolumn{3}{|l|}{ Values in the workplace } \\
\hline Lack of trust between employees & $1.20(1.05-1.38)$ & $1.09(0.98-1.22)$ \\
\hline Lack of trust regarding the management & $1.16(1.05-1.28)$ & $1.08(0.99-1.18)$ \\
\hline Lack of justice and respect & $1.18(1.08-1.30)$ & $1.11(1.03-1.19)$ \\
\hline Low social inclusiveness & $1.02(0.92-1.12)$ & $1.07(0.98-1.16)$ \\
\hline \multicolumn{3}{|l|}{ Mental health problems } \\
\hline Stress & $1.35(1.20-1.53)$ & $1.34(1.20-1.49)$ \\
\hline Somatic stress symptoms & $1.71(1.44-2.02)$ & $1.51(1.32-1.73)$ \\
\hline Cognitive stress symptoms & $1.19(1.06-1.34)$ & $1.14(1.03-1.25)$ \\
\hline Depression symptoms & $1.19(1.06-1.33)$ & $1.23(1.11-1.37)$ \\
\hline Sleeping troubles & $1.21(1.09-1.34)$ & $1.16(1.06-1.27)$ \\
\hline Burnout & $1.23(1.10-1.39)$ & $1.32(1.18-1.48)$ \\
\hline
\end{tabular}

${ }^{*}$ Adjusted for age and self-rated health.

Our study had some important limitations. First, despite providing repeated reminders, the response rate to requests to participate in the survey was modest. Nonetheless, the study sample was homogeneous according to average age ( 40 years) and working experience (56\% and 54\%, resp.). Second, the cross-sectional design of the study left some uncertainty about the causal relationship between dependent and independent variables. Third, the assessment of exposures was based on self-reporting. It could be that distress caused by
MSP made some participants more likely to report poorer mental health, affecting their scores for PSFs.

\section{Conclusions}

This study suggests that the prevalence of MSP among hospital nurses is high. Lower back and neck are body areas most frequently affected by pain. Work-related psychosocial risk factors (quantitative and emotional demands, work 
pace, low justice and respect in the workplace, influence on work organisation, and role conflicts) and mental health problems, especially somatic stress symptoms, appear to have an important impact on the occurrence of musculoskeletal pain among university hospital nurses. The results of this study suggest that there would be an improvement in the PS work environment of hospital nurses.

$\begin{array}{ll}\text { Abbreviations } \\ \text { CI: } & \text { Confidence interval } \\ \text { COPSOQ: } & \text { Copenhagen Psychosocial Questionnaire } \\ \text { MHPs: } & \text { Mental health problems } \\ \text { MSP: } & \text { Musculoskeletal pain } \\ \text { PSFs: } & \text { Psychosocial work factors } \\ \text { NMQ: } & \text { Nordic Musculoskeletal Questionnaire } \\ \text { SD: } & \text { Standard deviation. }\end{array}$

\section{Additional Points}

Availability of Supporting Data. The datasets generated and analysed during the current study are not publicly available to preserve the privacy of participants; however they are available from the corresponding author on reasonable request.

\section{Ethical Approval}

The study was approved by the Research Ethics Committee of the University of Tartu (protocol number 202T-19) and conducted in accordance with the Helsinki Declaration.

\section{Consent}

The voluntary and anonymous nature of participation was emphasized in the letter of invitation and through verbal communication.

\section{Competing Interests}

The authors declare they have no competing interests.

\section{Authors' Contributions}

Tiina Freimann conducted study conception, design, analysis and interpretation of data, and drafting the manuscript. Eda Merisalu and Mati Pääsuke conducted supervisions to study design and interpretation of data and critical revisions to the drafts. All authors read and approved the final manuscript.

\section{Acknowledgments}

Tiina Freimann's studies were supported by the European Social Fund's Doctoral Studies and Internationalisation Programme DoRa. DoRa is administered by the Archimedes Foundation.

\section{References}

[1] Terviseamet, "Kutsehaigestumine ja tööst põhjustatud haigestumine 2014. aastal," http://terviseamet.ee/tervishoid/toeoetervishoid/aruanded.html.
[2] D. R. Smith, N. Wei, L. Kang, and R.-S. Wang, "Musculoskeletal disorders among professional nurses in Mainland China," Journal of Professional Nursing, vol. 20, no. 6, pp. 390-395, 2004.

[3] E. C. Alexopoulos, A. Burdorf, and A. Kalokerinou, "Risk factors for musculoskeletal disorders among nursing personnel in Greek hospitals," International Archives of Occupational and Environmental Health, vol. 76, no. 4, pp. 289-294, 2003.

[4] A. Choobineh, A. Rajaeefard, and M. Neghab, "Association between perceived demands and musculoskeletal disorders among hospital nurses of Shiraz University of Medical Sciences: a questionnaire survey," International Journal of Occupational Safety and Ergonomics, vol. 12, no. 4, pp. 409-416, 2006.

[5] D. P. Anap, C. Iyer, and K. Rao, "Work related musculoskeletal disorders among hospital nurses in rural Maharashtra, India: a multi centre survey," International Journal of Research in Medical Sciences, vol. 1, no. 2, pp. 101-107, 2013.

[6] D. R. Smith, M.-A. Choe, M. Y. Jeon, Y. R. Chae, G. J. An, and J. S. Jeong, "Epidemiology of musculoskeletal symptoms among Korean hospital nurses," International Journal of Occupational Safety and Ergonomics, vol. 11, no. 4, pp. 431-440, 2005.

[7] D. R. Smith, M. Mihashi, Y. Adachi, H. Koga, and T. Ishitake, "A detailed analysis of musculoskeletal disorder risk factors among Japanese nurses," Journal of Safety Research, vol. 37, no. 2, pp. 195-200, 2006.

[8] H. Harcombe, D. McBride, S. Derrett, and A. Gray, "Prevalence and impact of musculoskeletal disorders in New Zealand nurses, postal workers and office workers," Australian and New Zealand Journal of Public Health, vol. 33, no. 5, pp. 437-441, 2009.

[9] M. Josephson, M. Lagerström, M. Hagberg, and E. W. Hjelm, "Musculoskeletal symptoms and job strain among nursing personnel: a study over a three year period," Occupational and Environmental Medicine, vol. 54, no. 9, pp. 681-685, 1997.

[10] A. M. Trinkoff, J. A. Lipscomb, J. Geiger-Brown, and B. Brady, "Musculoskeletal problems of the neck, shoulder, and back and functional consequences in nurses," American Journal of Industrial Medicine, vol. 41, no. 3, pp. 170-178, 2002.

[11] B. R. Da Costa and E. R. Vieira, "Risk factors for workrelated musculoskeletal disorders: a systematic review of recent longitudinal studies," American Journal of Industrial Medicine, vol. 53, no. 3, pp. 285-323, 2010.

[12] P. M. Bongers, A. M. Kremer, and J. T. Laak, "Are psychosocial factors, risk factors for symptoms and signs of the shoulder, elbow, or hand/wrist?: a review of the epidemiological literature," American Journal of Industrial Medicine, vol. 41, no. 5, pp. 315-342, 2002.

[13] S. Leka and A. Jain, Health Impact of Psychosocial Hazards at Work: An Overview, World Health Organization, Geneva, Switzerland, 2010.

[14] D. Coggon, G. Ntani, K. T. Palmer et al., “The CUPID (Cultural and Psychosocial Influences on Disability) study: methods of data collection and characteristics of study sample," PLOS ONE, vol. 7, no. 7, Article ID e39820, 2012.

[15] B. Sherehiy, W. Karwowski, and T. Marek, "Relationship between risk factors and musculoskeletal disorders in the nursing profession: a systematic review," Occupational Ergonomics, vol. 4, no. 4, pp. 241-279, 2004.

[16] T. Freimann, D. Coggon, E. Merisalu, L. Animägi, and M. Pääsuke, "Risk factors for musculoskeletal pain amongst nurses in Estonia: A Cross-Sectional Study," BMC Musculoskeletal Disorders, vol. 14, article 334, 2013. 
[17] T. Freimann and E. Merisalu, "Work-related psychosocial risk factors and mental health problems amongst nurses at a university hospital in Estonia: a cross-sectional study," Scandinavian Journal of Public Health, vol. 43, no. 5, pp. 447-452, 2015.

[18] I. Kuorinka, B. Jonsson, A. Kilbom et al., "Standardised Nordic questionnaires for the analysis of musculoskeletal symptoms," Applied Ergonomics, vol. 18, no. 3, pp. 233-237, 1987.

[19] T. S. Kristensen, H. Hannerz, A. Høgh, and V. Borg, "The Copenhagen Psychosocial Questionnaire-a tool for the assessment and improvement of the psychosocial work environment," Scandinavian Journal of Work, Environment and Health, vol. 31, no. 6, pp. 438-449, 2005.

[20] J. H. Pejtersen, T. S. Kristensen, V. Borg, and J. B. Bjorner, “The second version of the Copenhagen PS Questionnaire," Scandinavian Journal of Public Health, vol. 38, no. 3, supplement, pp. 8-24, 2010.

[21] A. Nilsson, P. Lindberg, and E. Denison, "Predicting of pain, disability, and sick leave regarding a non-clinical sample among Swedish nurses," Scandinavian Journal of Pain, vol. 1, no. 3, pp. 160-166, 2010.

[22] D. R. Smith, K. Ohmura, Z. Yamagata, and J. Minai, "Musculoskeletal disorders among female nurses in a rural Japanese hospital," Nursing and Health Sciences, vol. 5, no. 3, pp. 185-188, 2003.

[23] T. Malloy and B. Penprase, "Nursing leadership style and psychosocial work environment," Journal of Nursing Management, vol. 18, no. 6, pp. 715-725, 2010.

[24] I. Seppo, J. Järve, E. Kallaste, L. Kraut, and M. Voitka, Psühhosotsiaalsete Riskide Levik Eestis, Center for Applied Research, CENTAR, 2010, http://www.centar.ee/uus/wp-content/uploads/ 2010/03/CENTAR_6pparuanne.pdf.

[25] B. Aust, R. Rugulies, J. Skakon, T. Scherzer, and C. Jensen, "Psychosocial work environment of hospital workers: validation of a comprehensive assessment scale," International Journal of Nursing Studies, vol. 44, no. 5, pp. 814-825, 2007.

[26] J. Smedley, H. Inskip, F. Trevelyan, P. Buckle, C. Cooper, and D. Coggon, "Risk factors for incident neck and shoulder pain in hospital nurses," Occupational and Environmental Medicine, vol. 60, no. 11, pp. 864-869, 2003.

[27] E. Bos, B. Krol, L. van der Star, and J. Groothoff, "Risk factors and musculoskeletal complaints in non-specialized nurses, IC nurses, operation room nurses, and X-ray technologists," International Archives of Occupational and Environmental Health, vol. 80, no. 3, pp. 198-206, 2007.

[28] B. I. J. M. Van der Heijden, E. Demerouti, A. B. Bakker, and The NEXT Study Group Coordinated by Hans-Martin Hasselhorn, "Work-home interference among nurses: reciprocal relationships with job demands and health," Journal of Advanced Nursing, vol. 62, no. 5, pp. 572-584, 2008.

[29] E. Solidaki, L. Chatzi, P. Bitsios et al., "Work-related and psychological determinants of multisite musculoskeletal pain," Scandinavian Journal of Work, Environment and Health, vol. 36, no. 1, pp. 54-61, 2010.

[30] K. Matsudaira, K. T. Palmer, I. Reading, M. Hirai, N. Yoshimura, and D. Coggon, "Prevalence and correlates of regional pain and associated disability in Japanese workers," Occupational and Environmental Medicine, vol. 68, no. 3, pp. 191-196, 2011.

[31] M. Carugno, A. C. Pesatori, M. M. Ferrario et al., "Physical and psychosocial risk factors for musculoskeletal disorders in Brazilian and Italian nurses," Cadernos de Saude Publica, vol. 28, no. 9, pp. 1632-1642, 2012. 


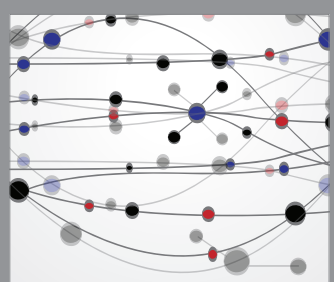

The Scientific World Journal
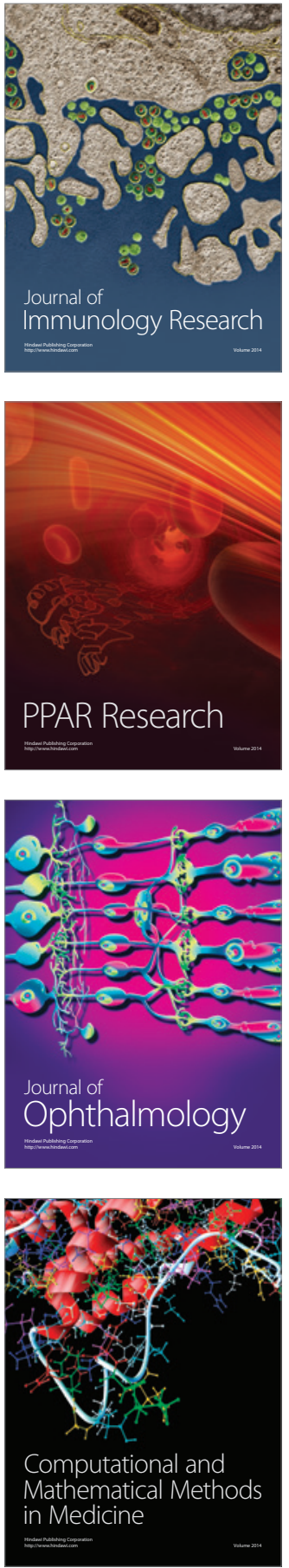

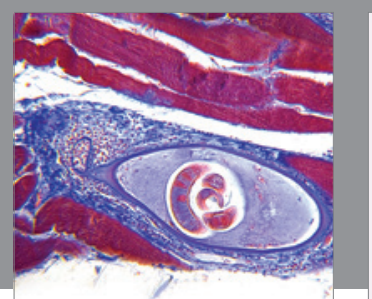

Gastroenterology Research and Practice

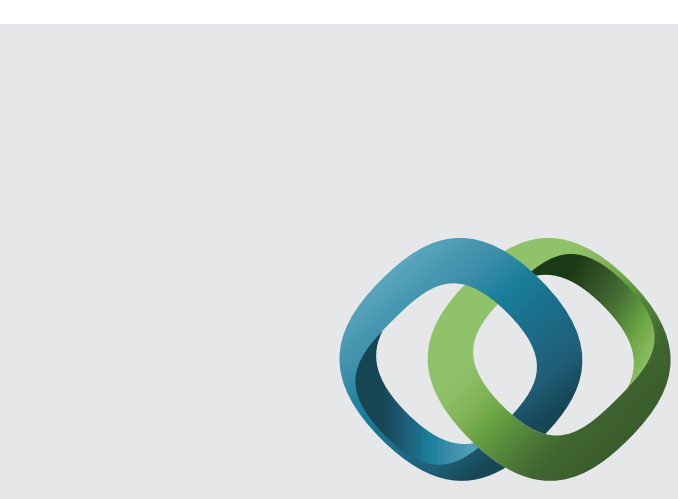

\section{Hindawi}

Submit your manuscripts at

http://www.hindawi.com
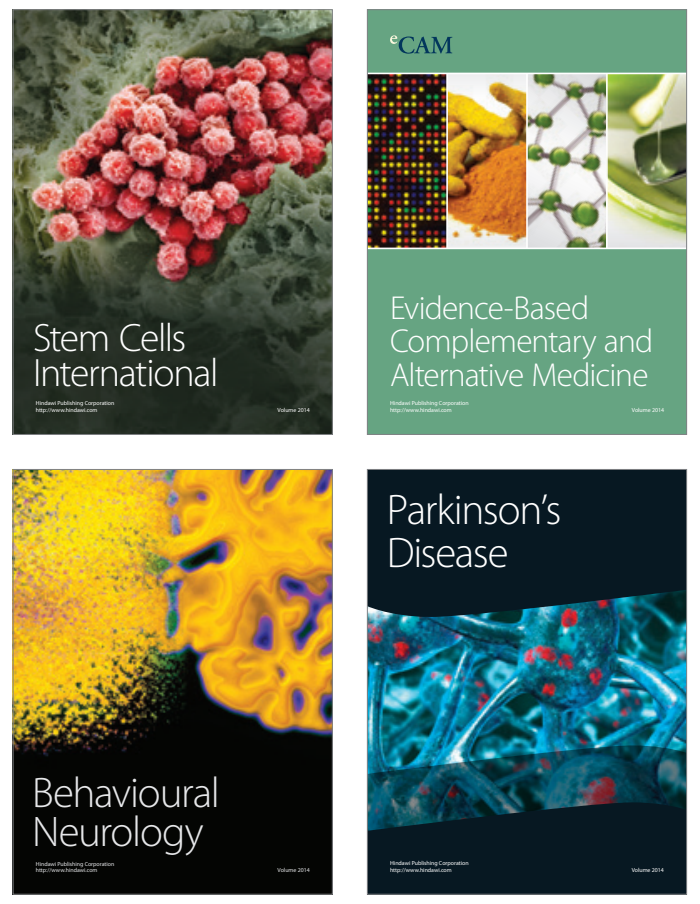
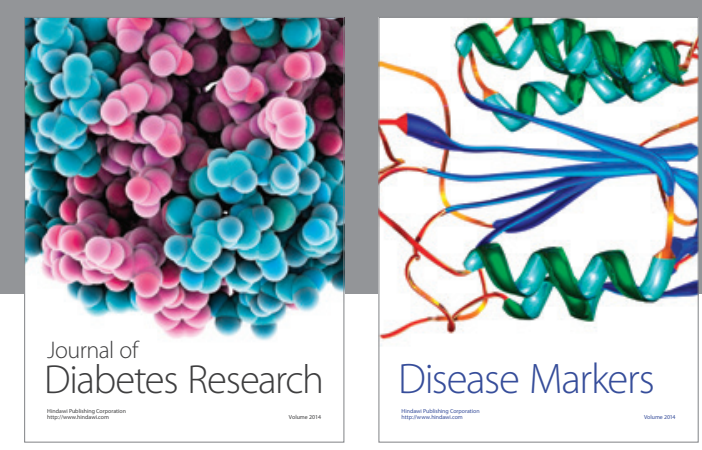

Disease Markers
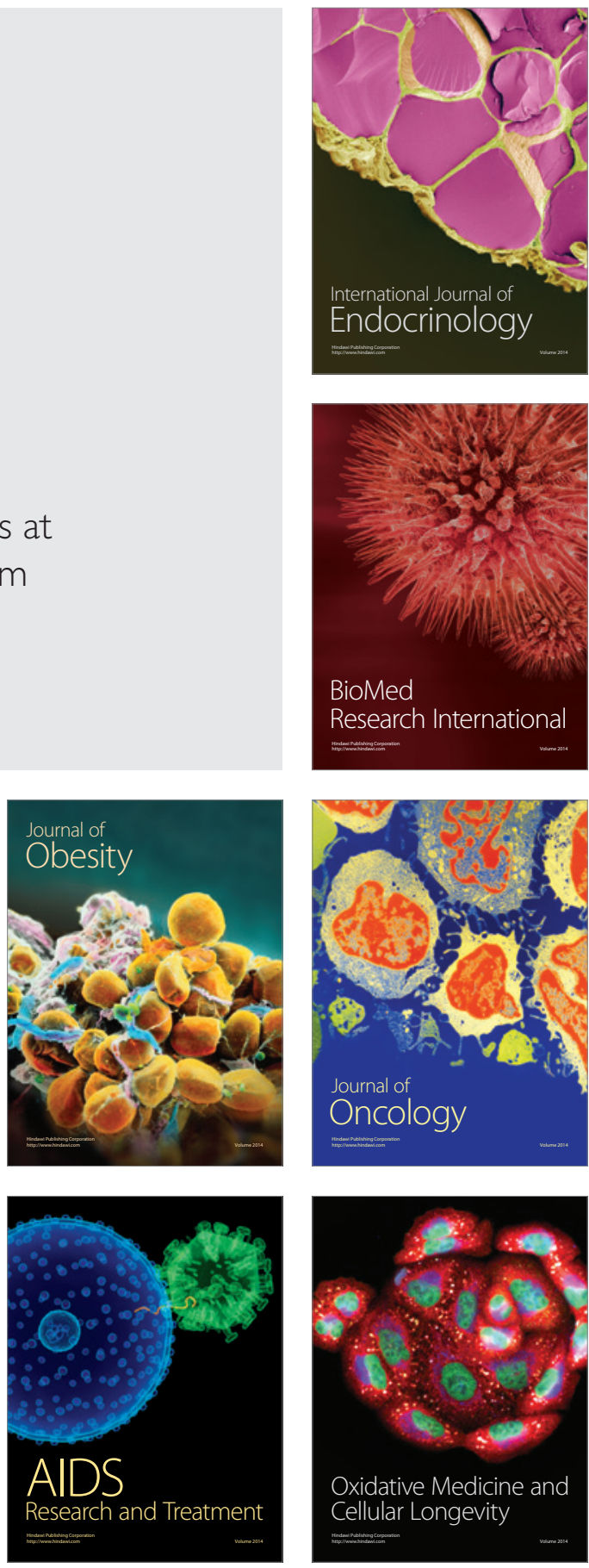